OPEN ACCESS

Edited by:

Chao Liang,

Hong Kong Baptist University,

Hong Kong

Reviewed by:

Li Hui,

Shaanxi Provincial People's Hospital,

China

Peng Cheng,

Nanjing Medical University, China

*Correspondence:

Ting Wen

tingwen163@126.com

Specialty section:

This article was submitted to

Molecular Medicine,

a section of the journal

Frontiers in Cell and Developmental

Biology

Received: 28 August 2020

Accepted: 20 October 2020

Published: 16 November 2020

Citation:

Peng $\mathrm{H}, \mathrm{He} \mathrm{H}-\mathrm{B}$ and Wen $\mathrm{T}$ (2020) A Novel Variant in CLCN7

Regulates the Coupling

of Angiogenesis and Osteogenesis.

Front. Cell Dev. Biol. 8:599826.

doi: 10.3389/fcell.2020.599826

\section{A Novel Variant in CLCN7 Regulates the Coupling of Angiogenesis and Osteogenesis}

\author{
Hui Peng ${ }^{1}$, Hong-Bo $\mathrm{He}^{2}$ and Ting Wen ${ }^{2 *}$ \\ 1 Department of Endocrinology, Endocrinology Research Center, Xiangya Hospital of Central South University, Changsha, \\ China, ${ }^{2}$ Department of Orthopedic, Xiangya Hospital of Central South University, Changsha, China
}

Autosomal dominant osteopetrosis type II (ADO II), characterized by increased bone mass and density, is caused by mutations in the chloride channel 7 (CLCN7) gene. In this study, a novel missense variant in CLCN7 (c.1678A > G; p.Met560Val) was identified in three symptomatic subjects and one carrier of a Chinese family with ADO II. Notably, bone formation markers, including osteocalcin and total procollagen type $\mathrm{N}$-terminal propeptide, have increased or presented at the upper limit of the normal range in the three patients. Serum factors secreted by osteoclast lineage cells and affecting the CD31 ${ }^{\text {hi }} E M C N^{\text {hi }}$ vessel formation, such as tartrate-resistant acid phosphatase $5 \mathrm{~b}$, platelet-derived growth factor-BB, vascular endothelial growth factor, and SLIT3, had a higher expression in three ADO II subjects than in 15 healthy age-matched and sexmatched controls. Moreover, the conditioned medium was obtained from preosteoclast induced from the ADO II patients' peripheral blood mononuclear cells. It was found to promote the CD31 ${ }^{\text {hi }}$ EMCN ${ }^{\text {hi }}$ vessel formation of human microvascular endothelial cells and osteogenic differentiation of bone marrow-derived stem cells. Taken together, our finding revealed a novel CLCN7 variant associated with ADO II and suggested that the sclerotic bone was potentially associated with the increase of the CD31 ${ }^{\text {hi }} E M C N^{\text {hi }}$ vessel formation and bone formation. Keywords: autosomal dominant osteopetrosis type II, CLCN7, variant, CD $31^{\text {hi }} \operatorname{Emcn}^{\text {hi }}$ vessel formation,
bone formation

\section{INTRODUCTION}

Autosomal dominant osteopetrosis type II (ADO II; OPTA2, Online Mendelian Inheritance in Man: 166600), also known as "Albers Schönberg disease," is the most common type of osteopetrosis with an estimated prevalence of 2.5/100,000 (Bénichou et al., 2000; Del Fattore et al., 2008). It is characterized by segmentary osteosclerosis, predominantly involving in the vertebral endplates ("rugger-jersey spine"), iliac wings ("bone within bone" sign), and the skull base. Previous studies revealed that ADO II was a phenotypically heterogeneous disease whose clinical spectrums ranged from unaffected radiography mutation carriers to affected skeletal patients yet asymptomatic to severe manifestations including fracture, osteomyelitis, visual loss, and bone marrow failure (Bénichou et al., 2000; Waguespack et al., 2007).

The bone homeostasis was maintained by balancing osteoclast-mediated resorption and osteoblast-mediated formation (Wang et al., 2018; Hayashi et al., 2019; Rodriguez-Laguna et al., 2019). The disrupted bone mass and structure of osteopetrosis resulted from the impaired 
osteoclast-mediated bone resorption caused by genetic factors (Tolar et al., 2004; Sobacchi et al., 2013). Bénichou et al. (2001) previously considered that ADO II was genetically homogeneous with a single disease-causing gene on 16p13.3. Accumulated studies showed that roughly $70 \%$ of patients harbored heterozygous missense mutations of the CLCN7 gene in a dominant-negative form (Cleiren et al., 2001). To date, more than 40 mutations in CLCN7 has been identified in different osteopetrosis families (Leisle et al., 2011; Pang et al., 2016). CLCN7 (Online Mendelian Inheritance in Man: 602727) is a multi-pass membrane protein that acts as a $\mathrm{Cl}-/ \mathrm{H}+$ exchanger by voltage gate (Leisle et al., 2011). It mainly resides in the late endosomes, lysosomes, and the ruffled membrane of osteoclasts. In osteoclasts, the ruffled border contains $\mathrm{Cl}$-channels that are inserted by exocytotic fusion together with the $\mathrm{H}+$-ATPase to ensure the acidification of extracellular resorption lacuna. Pathogenic mutations in the CLCN7 gene impairing acidification of extracellular resorption lacuna were assumed to prevent degradation of the calcified and organic matrix of bone (Weinert et al., 2010). Furthermore, some studies suggested that chloride channels could be a drug target for osteopetrosis (Capulli et al., 2015). Mattia et al. demonstrated that CLCN7 mutant-specific small interfering RNAs silenced dominant-negative CLCN7 transcripts and subsequently ameliorated the bone phenotype in ADO II (Verkman and Galietta, 2009). Recent research also demonstrated that the specific small interfering RNA therapy normalized extra-skeletal manifestations on the ADO II mouse (Maurizi et al., 2019).

Some studies suggested that CLCN7 mutations regulate bone formation in patients with osteopetrosis (Barvencik et al., 2014; Coudert et al., 2014). The vessels in the bone niche were reported to play great roles in bone formation (Abarrategi et al., 2018; Hao et al., 2019). A specific endothelium in the murine skeletal system, termed type $\mathrm{H}$, strongly positive for CD31 and endomucin, is crucial in bone formation and regeneration (Kusumbe et al., 2014; Ramasamy et al., 2014; Langen et al., 2017). Accumulated evidence suggests that the type $H$ vessels exert on bone formation in many aspects, ranging from mediating local growth of the vasculature, to providing a necessary microenvironment for perivascular osteoprogenitors, and coupling angiogenesis to osteogenesis (Yang et al., 2017). Previous findings revealed that platelet-derived growth factor-BB (PDGF-BB) secreted by preosteoclast could induce $\mathrm{CD} 31^{\text {hi }} \mathrm{Emcn}^{\text {hi }}$ vessels subtype subsequently prevented bone loss in osteoporosis and boneloss diseases (Xie et al., 2014). Furthermore, we recently found a mutation in Reg1cp involved in high bone mass syndrome through promoting angiogenesis (Yang et al., 2019). However, whether the bone accrual is associated with the coupling between angiogenesis and osteogenesis or not remains unclear.

Here, we ascertained a missense variant in CLCN7 in a Chinese family. This is the first description genetically confirmed with this heterozygous missense mutation (c.1678A $>\mathrm{G}$; p. Met560Val) responsible for ADO II. Additionally, these results indicated that the mutation might be associated with the dysfunction of the angiogenesis and osteogenesis, which further explained the elevated bone formation markers in this ADO II family.

\section{MATERIALS AND METHODS}

\section{Family Collection}

The Chinese family who suffered from ADO II was recruited from Xiangya Hospital Central South University. There were three affected individuals (II3, II7, and III2 in Figure 1A) in this family, and all of the affected subjects were not born of consanguineous parents. The patients underwent a series of clinical evaluation including laboratory and radiography examination in Xiangya Hospital, such as blood route, liver function test, renal function test, serum calcium $(\mathrm{Ca})$, phosphate (P), alkaline phosphatase (ALP), $\beta$-Cross Laps of type I collagen containing cross-linked C-telopeptide, osteocalcin (OC), total procollagen type $\mathrm{N}$-terminal propeptide (TPINP), and intact parathyroid hormone (PTH). Additionally, the patients were carried out with bone mineral density of the total body measured by a dual-energy X-ray absorptiometry densitometer and X-ray of bilateral hip joints and lumbar. The study was approved by the Ethics Committee of Xiangya Hospital Central South University. All subjects involved in this study signed informed consent documents before participating in the project.

\section{Whole-Genome Sequence}

Genomic DNA was collected and extracted from peripheral whole blood samples using Qiagen DNA kits. The genomic DNA met the sequencing requirements of the purity (optical density $260 / 280>1.8)$ and concentration $(50 \mathrm{ng} / \mathrm{ml})$ of each sample. Whole-genome sequencing was conducted by Annoroad Gene Technology by using Illumina/TruSeq Nano DNA HT Library Preparation Kit for capture and Illumina sequencing platforms for data generation (150-bp paired-end, 300 cycles). Sequencing was performed with 150 -bp paired-end reads on the Illumina NovaSeq 6000 sequencing platform. The mean coverage was $40 \times$.

\section{Variant Filtering and Analysis}

Sequence alignment was performed with the Burrows-Wheeler Aligner mem using human genome assembly hg19 as the reference, then produce called variants with RTG tools Hyplotype Caller. Annotation of gene context was carried out with annovar using Single Nucleotide Polymorphism Database, Refseq gene as the reference.

\section{Sanger Sequence}

The variant was amplified by using DNA polymerase [MIX (GREEN), TSINGKE, China], and the former and reverse primers are CTTGAGGAGTCCACACCCAC and CTGGGAGCAGGTGGATGG, respectively. Forward and reverse sequencing reactions were performed with the Big Dye Terminator Cycle Sequencing Ready Reaction Kit (PE Applied Biosystems), and the products were analyzed on an ABI 3730XL automated sequencer (PE Applied Biosystems).

\section{Enzyme-Linked Immunosorbent Assay}

Serum was obtained from peripheral blood using 4,000 rpm for $5 \mathrm{~min}$. Then, we used the ELISA kits to test the expression of tartrate-resistant acid phosphatase 5b (TRAP-5b), PDGF-BB, vascular endothelial growth factor (VEGF; R\&D Systems), and 
A

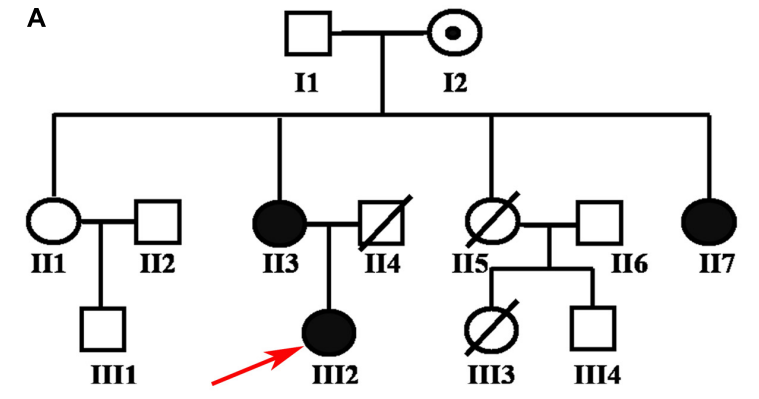

$\begin{array}{llllllllllllllllll}\text { B } & \text { T } & \text { C } & \text { C } & \text { C } & \text { C } & \text { A } & \text { T } & \text { C } & \text { A } & \text { T } & \text { G } & \text { C } & \text { T } & G & G & \mathbf{T} & \mathbf{G}\end{array}$

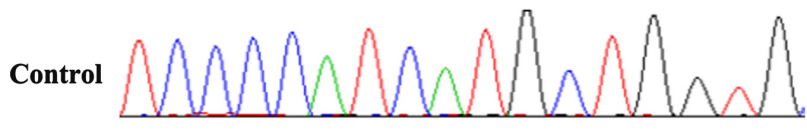

$\underset{\text { patient }}{\text { III2 }}$

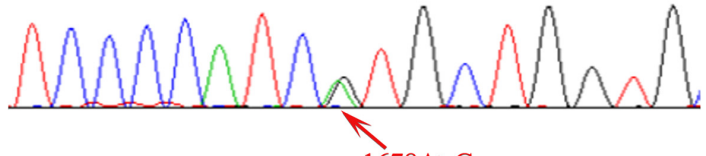

C

III2
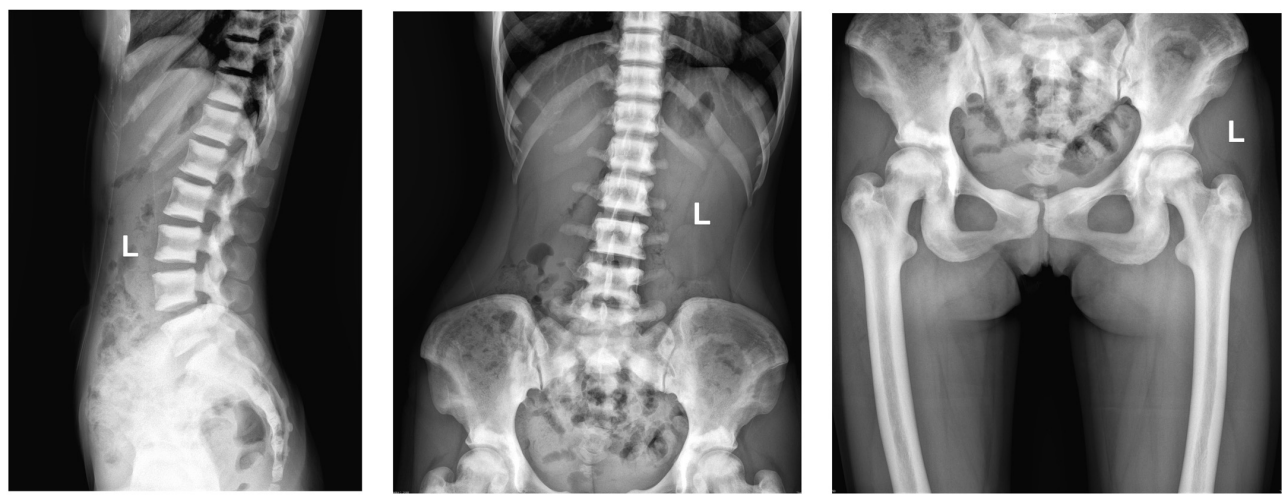

D
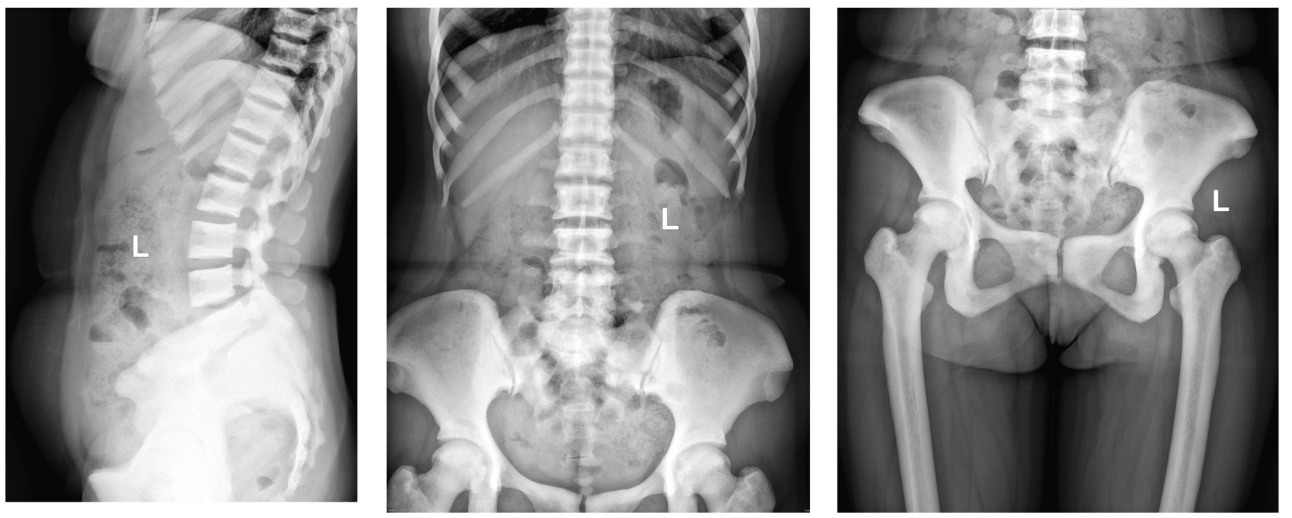

E

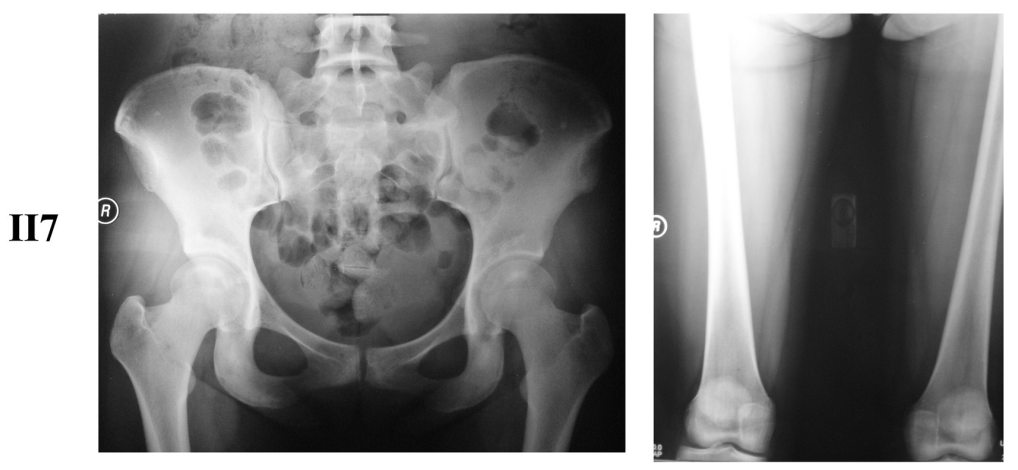

FIGURE 1 | Pedigree of the osteopetrosis family was associated with the mutation in CLCN7. (A) Pedigree of a Chinese family with osteopetrosis. Squares represent males, and circles represent females. Red arrow indicates the proband in this family. White symbols represent unaffected subjects, and black symbols indicate affected subjects. Symbols with an embedded black dot represent asymptomatic carriers. Symbols with a diagonal line represent deceased subjects. (B) Sanger sequence chromatograms from the proband and unaffected II1. c.1678A > G transition is indicated by the red arrow. (C-E) Radiographic image reveals osteosclerosis in three affected patients (radiographic images of III2 in the top row, images of II3 in the second row, and images of II7 in the bottom row). Images showed vertebral endplates ("rugger-jersey spine"; III2 and II3) and osteosclerosis of the pelvis and femoral (III2, II3, and II7). 
SLIT3 (SED353Mi) in serum according to the manufacturers' instructions. The ELISA was replicated three times for the affected patients, and the mean values were used.

\section{Cell Culture}

A total of $15 \mathrm{ml}$ of heparin anti-coagulated peripheral blood was obtained from every subject, including all members of this family and healthy age- and sex-matched controls. Then, peripheral blood mononuclear cells (PBMCs) were washed using phosphate-buffered saline twice and cultured in minimum essential medium Eagle- $\alpha$ containing 10\% fetal bovine serum, $100 \mathrm{U} \mathrm{ml}^{-1}$ penicillin, $100 \mu \mathrm{g} \mathrm{ml}^{-1}$ streptomycin sulfate, and $50 \mathrm{ng} \mathrm{ml}^{-1}$ macrophage colony-stimulating factor (M-CSF; R\&D Systems Inc.). Non-adherent cells were incubated with M-CSF $\left(50 \mathrm{ng} \mathrm{ml}^{-1}\right.$ ) to obtain pure monocytes and macrophages. Then, PBMCs were cultured in 24-well plates at $1 \times 10^{5}$ cells per well with $50 \mathrm{ng} \mathrm{ml}^{-1}$ of M-CSF and $100 \mathrm{ng} \mathrm{ml}^{-1}$ receptor activator of nuclear factor-kappa-B ligand. Cells became preosteoclasts after a 3-day culture. We collected serum-containing conditioned medium from the preosteoclasts. After centrifugation $(2,500 \mathrm{rpm}$ for $10 \mathrm{~min}$ at $4^{\circ} \mathrm{C}$ ), we aliquoted conditioned media and stored them at $-80^{\circ} \mathrm{C}$. Human BMSCs (HUXMA-0100; Cyagen Biosciences) were cultured in a human mesenchymal stem cell growth medium (HUXMA-90011; Cyagen Biosciences). To induce osteogenic differentiation of BMSCs, BMSCs were cultured in 48-well using the serum-containing conditioned medium. Then, we collected protein to test ALP activity on day 2, RNA on the 3rd day, and performed the ALP staining on day 7. Human microvascular endothelial cells (HMECs) were cultured with MCDB131 medium (Gibco) supplemented 10\% fetal bovine serum, $100 \mathrm{U} \mathrm{ml}^{-1}$ penicillin, and $100 \mu \mathrm{g} \mathrm{ml}^{-1}$ streptomycin.

\section{Real-Time Quantitative Polymerase Chain Reaction}

Quantitative PCR analysis was performed as described previously (Xiao et al., 2020). Briefly, we extracted RNA from cells using Trizol reagent (Takara). Then, 1,000-ng RNA was reversetranscribed into first-strand complementary DNA using the Reverse Transcription Kit (Takara). Quantitative PCR was performed using SYBR Green PCR Master Mix (Takara), and messenger RNA expression was normalized to reference genes GAPDH.

\section{Tube Formation Assay}

The Matrigel (BD Biosciences) was plated in 48-well plates and then incubated at $37^{\circ} \mathrm{C}$ for $45 \mathrm{~min}$. HMECs were seeded in 48 -well plates at $5 \times 10^{4}$ cells per well on polymerized Matrigel. The cells were cultured in the preosteoclast-conditioned medium collected from patients or control individuals for $4 \mathrm{~h}$ incubation at $37^{\circ} \mathrm{C}$. Then, the tube formation was observed through microscopy, and the number of tube branches was quantified in four random microscope visual fields of each well.

\section{Alkaline Phosphatase Activity}

On the second day of osteogenic differentiation, the cell lysates were homogenized for ALP activity assay by spectrophotometric measurement of $p$-nitrophenol release using an ALP Assay Kit (P0321S, Beyotime) according to the manufacturer's instructions.

\section{Alkaline Phosphatase Staining}

The cells were washed using phosphate-buffered saline for three times, followed by $10 \%$ paraformaldehyde for $5 \mathrm{~min}$. Then, cells were incubated in ALP incubation buffer (0.2- $g$ barbital sodium, $0.4-g$ magnesium sulfate, $0.2-g$ calcium chloride, and $0.3-g$ beta-glycerophosphate) at $37^{\circ} \mathrm{C}$ for $2 \mathrm{~h}$. Next, cells were washed with $2 \%$ calcium chloride and incubated with $2 \%$ cobaltous nitrate for $5 \mathrm{~min}$. Finally, cells were incubated in 1:80 ammonium sulfate for $10 \mathrm{~s}$. The ALP staining was observed through a microscope.

\section{Statistical Analysis}

Data were imported into Excel and scaled and normalized to appropriate controls. Unpaired, two-tailed Student's $t$-tests were performed for the comparisons of two groups. Critical $P$-values were Bonferroni corrected and expressed as follows: ${ }^{\star} P<0.05 .{ }^{\star} P<0.01$.

\section{RESULTS}

\section{Clinical Characteristics of Patients}

A Chinese patient, aged 22 years, was admitted to the Department of Endocrinology with a history of bone pain for 6 years. There was a family history of a similar disease of her mother (II3) and aunt (II7) shown in Figure 1A. All these three patients had a mild phenotype of osteopetrosis only with bone pain on hip joints and back. The proband also had a history of fracture in the hip. On examination, we did not find poor nutritional status, short stature, malformed craniofacial appearance, hepatosplenomegaly, and intellectual disability in the proband and other affected patients in this family.

Laboratory findings of the three patients showed that the hematopoietic function, liver function, kidney function, total serum calcium, and total serum phosphorus were within the normal ranges except for a slight increase of aspartate transaminase of II3 (Table 1). For bone turnover markers, $\beta$ cross-linked C-telopeptide of type 1 collagen and ALP have not detected any abnormalities in this family (Table 2). However, markers of bone formation in the proband, such as OC and TPINP, were both found at the upper limit of the normal range (Table 2). Moreover, the levels of OC, TPINP, and PTH (parathormone) were found to be elevated in her mother (II3). The level of OC in her aunt (II7) also slightly increased. Thus, we hypothesized that bone formation in these patients had been elevated (Table 2).

The total bone mineral density values of the three patients at lumbar and hip sites, measured by dual-energy X-ray absorptiometry, are shown in Table 3. The three affected patients were all with regular menstruation. The $Z$ values at different sites of the three patients were significantly higher than the those of the sex-matched and age-matched 
TABLE 1 | Hematopoietic, hepatorenal, and serum electrolytic data of ADO II subjects.

\begin{tabular}{lcccc}
\hline Parameters & III2 & II3 & II7 & Normal range \\
\hline $\mathrm{WBC}\left(10^{9} \cdot \mathrm{L}^{-1}\right)$ & 4.2 & 5.3 & 5.46 & $3.5-9.5$ \\
$\mathrm{Hb}\left(\mathrm{g} \cdot \mathrm{L}^{-1}\right)$ & 124 & 126 & 126 & $115-150$ \\
$\mathrm{RBC}\left(10^{12} \cdot \mathrm{L}^{-1}\right)$ & 4.52 & 4.34 & 4.19 & $3.80-5.10$ \\
$\mathrm{PLT}\left(10^{9} \cdot \mathrm{L}^{-1}\right)$ & 295 & 240 & 146 & $125-350$ \\
$\mathrm{ALT}(\mu / \mathrm{L})$ & 9.3 & 21.6 & 20.4 & $7.0-40.0$ \\
$\mathrm{AST}(\mu / \mathrm{L})$ & 32.4 & 46.5 & 22.5 & $13.0-35.0$ \\
$\mathrm{BUN}(\mathrm{mmol} / \mathrm{L})$ & 4.58 & 5.56 & 6.95 & $2.60-7.50$ \\
$\mathrm{Cre}(\mu \mathrm{mol} / \mathrm{L})$ & 55 & 69 & 53 & $41.0-111.0$ \\
$\mathrm{UA}(\mu \mathrm{mol} / \mathrm{L})$ & 287.5 & 289.5 & 246 & $155.0-357.0$ \\
$\mathrm{Na}(\mathrm{mmol} / \mathrm{L})$ & 140 & 142.8 & 142 & $137.0-147.0$ \\
$\mathrm{~K}(\mathrm{mmol} / \mathrm{L})$ & 4.54 & 4.22 & 3.6 & $3.50-5.30$ \\
$\mathrm{Cl}(\mathrm{mmol} / \mathrm{L})$ & 103.4 & 107.8 & 105.6 & $99.0-110.0$ \\
$\mathrm{Ca}(\mathrm{mmol} / \mathrm{L})$ & 2.45 & 2.28 & 2.22 & $2.00-2.60$ \\
$\mathrm{Mg}(\mathrm{mmol} / \mathrm{L})$ & 0.91 & 0.84 & 0.98 & $0.66-1.07$ \\
$\mathrm{P}(\mathrm{mmol} / \mathrm{L})$ & 1.41 & 1.45 & 1.25 & $0.86-1.78$ \\
\hline
\end{tabular}

WBC, white blood cells; RBC, red blood cells; Hb, hemoglobin; PLT, platelet; ALT, alanine transaminase; $A S T$, aspartate transaminase; BUN, blood urea nitrogen; Cre, creatinine; and UA, uric acid.

TABLE 2 | Bone biomarker of ADO || subjects.

\begin{tabular}{lcccc}
\hline & III2 & II3 & II7 & Normal range \\
\hline ALP $(\mu / \mathrm{L})$ & 55.3 & 64.5 & 46.8 & $45.0-125.0$ \\
OC $(\mathrm{ng} / \mathrm{ml})$ & 20.44 & 26.79 & 45 & $4.11-21.87$ \\
TPINP $(\mathrm{ng} / \mathrm{ml})$ & 58.37 & 131.4 & NA & $8.53-64.32$ \\
PTH $(\mathrm{pg} / \mathrm{ml})$ & 44.8 & 83.8 & 59.85 & $15.0-68.3$ \\
$\beta-\mathrm{CTX}(\mathrm{pg} / \mathrm{ml})$ & 290.5 & 243.5 & 572 & $68-680$ \\
\hline
\end{tabular}

ALP, alkaline phosphatase; OC, osteocalcin; TPINP, total procollagen type $N$-terminal propeptide; PTH, parathormone; $\beta$-CTX, $\beta$ cross-linked C-telopeptide of type 1 collagen; and NA, not available.

TABLE 3 | Bone mass density of the ADO || subjects.

\begin{tabular}{|c|c|c|c|c|c|c|c|}
\hline \multirow[t]{2}{*}{ Subjects } & \multirow[t]{2}{*}{ Age } & \multirow{2}{*}{$\begin{array}{c}\text { Total } \\
\text { Total } \\
\text { BMD } \\
\left(\mathrm{g} / \mathrm{cm}^{2}\right)\end{array}$} & \multirow[b]{2}{*}{$\begin{array}{c}Z \\
\text { value }\end{array}$} & \multirow{2}{*}{$\begin{array}{c}\text { Lumbar } \\
\text { Total } \\
\text { BMD } \\
\left(\mathrm{g} / \mathrm{cm}^{2}\right)\end{array}$} & \multirow[b]{2}{*}{$\begin{array}{c}Z \\
\text { value }\end{array}$} & \multirow{2}{*}{$\begin{array}{c}\text { Left hip } \\
\text { Total } \\
\text { BMD } \\
\left(\mathrm{g} / \mathrm{cm}^{2}\right)\end{array}$} & \multirow[b]{2}{*}{$\begin{array}{c}Z \\
\text { value }\end{array}$} \\
\hline & & & & & & & \\
\hline III2 & 21 & 1.611 & 5.8 & 2.221 & 12.1 & 1.591 & 6.9 \\
\hline 113 & 42 & 2.063 & 8.0 & 2.304 & 12.7 & 1.918 & 9.6 \\
\hline 117 & 29 & 1.973 & 7.6 & 2.245 & 11.2 & 1.855 & 8.3 \\
\hline
\end{tabular}

$B M D$, Bone mineral density.

controls (Table 3). Radiological features of the three patients revealed diffused osteosclerosis, predominantly at the vertebral endplates ("rugger-jersey spine"). The superior ramus of the pubis, sacral vertebrae, femoral head, and greater trochanter of femur also presented diffuse osteosclerosis. The boundaries among cancellous bone, cortical bone, and bone medullary disappeared (Figures 1C-E). Based on their clinical and radiological assessment, the family was diagnosed with ADO II.

\section{Genetic Analysis With Whole-Genome Sequencing and Identification of the Pathogenic Variant}

We performed the whole-genome sequence in the three affected patients. Firstly, we filtered the common variants, which were unlikely to cause the rare heritable disorder (allele frequency greater than $0.1 \%$ in the 1000 Genomes database and Exome Variant Server). Then, we excluded the variants with low confidence and the putative impact. Next, we tried to find the shared variant in the three patients. Interestingly, a heterozygous missense variant (c.1678A > G, p.Met560Val) in CLCN7 segregated with osteopetrosis among three affected patients. We then performed the Sanger sequence in all members of this family and found the variant occurred in three patients and a non-penetrant carrier (I2 in Figure 1A was asymptomatic and did not present abnormal bone phenotype as well as laboratory findings; Figure 1B).

Various mutations in CLCN7 have been reported to be involved in the pathogenesis of osteopetrosis (Figure 2). In gnomAD database, the PopMax Allele Frequency and allele count of this variant were 0.00000900058 and 1, respectively, (the total Allele number was 245442). Moreover, this variant was not found in East Asian with 17228 Allele number in total. Pro560 in CLCN7, which is substituted to a Valine in three patients, is phylogenetically highly conserved among both vertebrates and invertebrates (Figure 3) [Phylop] score of 6.111 and [PhastCons] score of 1. CLCN7 gene was also predicted to be intolerant whose Residual Variation Intolerance Score is $7.0381 \%$ (Table 4). Furthermore, the effect of missense mutation Met560Val in CLCN7 was predicted by different variant effect prediction software (PolyPhen-2, MutationTaster, CADD, MPC). It suggested that the Met560Val substitution is likely to be deleterious (PolyPhen score of 0.991, probably damaging; MutationTaster score of 0.999, disease-causing; CADD score of 24.3, damaging; MPC score of 1.0788, possibly damaging; Table 4). Based on the genetic analysis, this study revealed that the heterozygous missense mutation was possibly responsible for the $\mathrm{ADO}$ II.

\section{CLCN7 Mutation Induces the Type H Vessel Formation and Osteogenic Differentiation in vitro}

The cross-talks between osteoclasts and other cells, including osteoblasts, endothelium cells, have been well established (Phan et al., 2004; Ramasamy et al., 2014; Xie et al., 2014; Yang et al., 2017, 2019; Chen et al., 2018; Li et al., 2019). Additionally, PDGF-BB secreted by preosteoclasts could result in elevated bone mass through inducing angiogenesis during coupling with osteogenesis (Xie et al., 2014). To investigate if the osteosclerotic bone of these patients was associated with the coupling between angiogenesis and osteogenesis, we collected the serum from ADO II individuals and 15 normal controls for further studies. TRAP-5b is well-established to be secreted by osteoclasts, and PDGF-BB, VEGF, and SLIT3 can also be secreted by osteoclasts/preosteoclasts, which were reported to be 


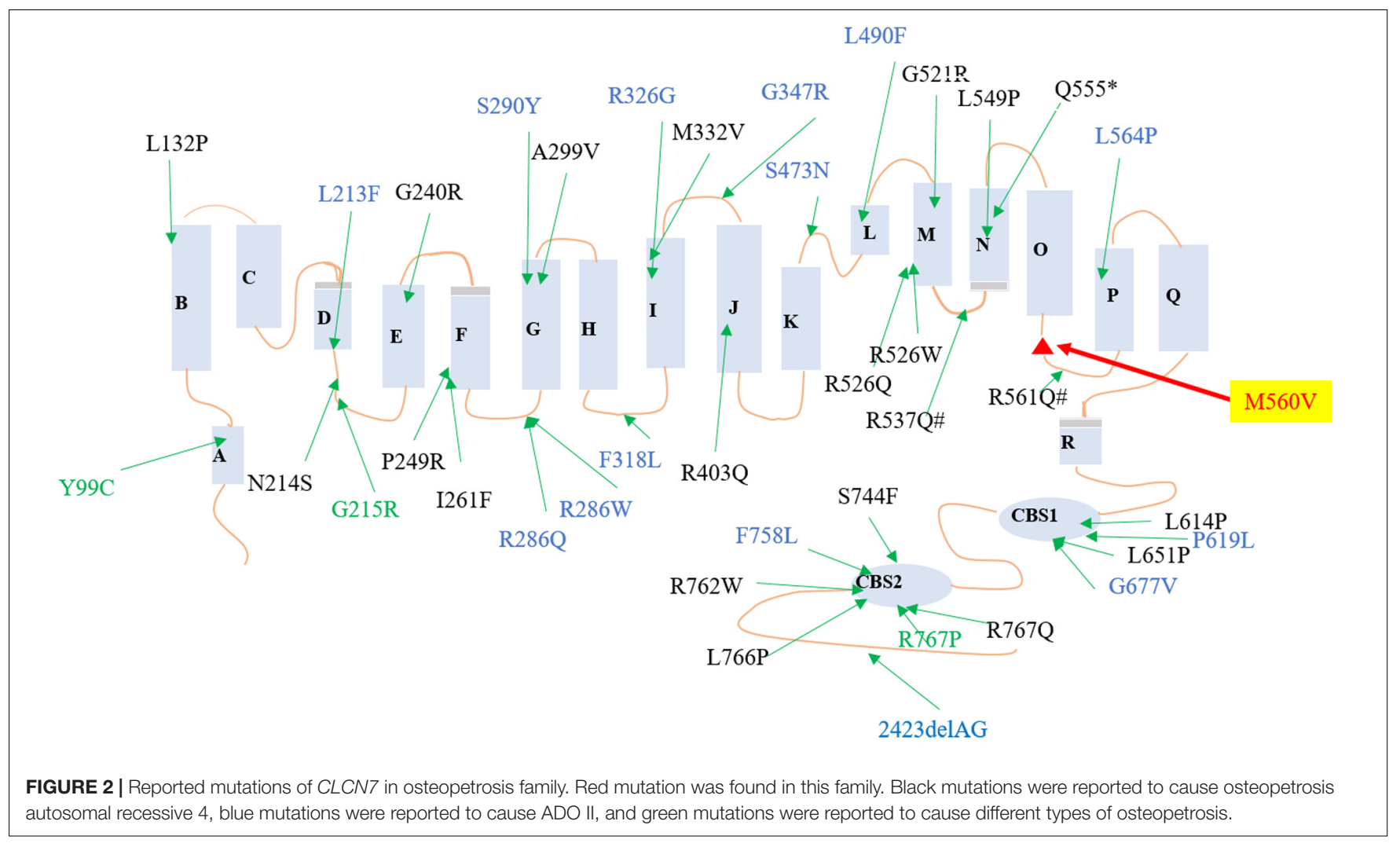

FIGURE 2 | Reported mutations of CLCN7 in osteopetrosis family. Red mutation was found in this family. Black mutations were reported to cause osteopetrosis autosomal recessive 4, blue mutations were reported to cause ADO II, and green mutations were reported to cause different types of osteopetrosis.

\begin{tabular}{|c|c|c|}
\hline $\begin{array}{l}\text { H.sapiens } \\
\text { M.mulatta } \\
\text { M.musculus } \\
\text { C.familiaris } \\
\text { Rattus } \\
\text { G.galus } \\
\text { D.rerio }\end{array}$ & $\begin{array}{lllllllllll}\mathrm{G} & \mathrm{V} & \mathrm{I} & \mathrm{K} & \mathrm{A} & \mathrm{T} & \mathrm{M} & \mathrm{L} & \mathrm{V} & \mathrm{L} & \mathrm{M} \\
\mathrm{G} & \mathrm{V} & \mathrm{I} & \mathrm{K} & \mathrm{A} & \mathrm{T} & \mathrm{M} & \mathrm{L} & \mathrm{V} & \mathrm{L} & \mathrm{M} \\
\mathrm{G} & \mathrm{V} & \mathrm{I} & \mathrm{K} & \mathrm{A} & \mathrm{T} & \mathrm{M} & \mathrm{L} & \mathrm{V} & \mathrm{L} & \mathrm{M} \\
\mathrm{G} & \mathrm{V} & \mathrm{I} & \mathrm{K} & \mathrm{A} & \mathrm{T} & \mathrm{M} & \mathrm{L} & \mathrm{V} & \mathrm{L} & \mathrm{M} \\
\mathrm{G} & \mathrm{V} & \mathrm{I} & \mathrm{K} & \mathrm{A} & \mathrm{T} & \mathrm{M} & \mathrm{L} & \mathrm{V} & \mathrm{L} & \mathrm{M} \\
\mathrm{G} & \mathrm{V} & \mathrm{I} & \mathrm{K} & \mathrm{A} & \mathrm{T} & \mathrm{M} & \mathrm{L} & \mathrm{V} & \mathrm{L} & \mathrm{M} \\
\mathrm{G} & \mathrm{V} & \mathrm{I} & \mathrm{K} & \mathrm{A} & \mathrm{T} & \mathrm{M} & \mathrm{L} & \mathrm{V} & \mathrm{L} & \mathrm{M}\end{array}$ & $\begin{array}{llllllllll}\mathrm{I} & \mathrm{P} & \mathrm{F} & \mathrm{G} & \mathrm{Y} & \mathrm{T} & \mathrm{V} & \mathrm{N} & \mathrm{S} & \mathrm{T} \\
\mathrm{I} & \mathrm{P} & \mathrm{F} & \mathrm{G} & \mathrm{Y} & \mathrm{T} & \mathrm{V} & \mathrm{N} & \mathrm{S} & \mathrm{T} \\
\mathrm{I} & \mathrm{P} & \mathrm{F} & \mathrm{G} & \mathrm{Y} & \mathrm{T} & \mathrm{V} & \mathrm{N} & \mathrm{S} & \mathrm{T} \\
\mathrm{I} & \mathrm{P} & \mathrm{F} & \mathrm{G} & \mathrm{Y} & \mathrm{T} & \mathrm{V} & \mathrm{N} & \mathrm{S} & \mathrm{T} \\
\mathrm{I} & \mathrm{P} & \mathrm{F} & \mathrm{G} & \mathrm{Y} & \mathrm{T} & \mathrm{V} & \mathrm{N} & \mathrm{S} & \mathrm{T} \\
\mathrm{I} & \mathrm{P} & \mathrm{F} & \mathrm{G} & \mathrm{Y} & \mathrm{T} & \mathrm{V} & \mathrm{N} & \mathrm{S} & \mathrm{T} \\
\mathrm{I} & \mathrm{P} & \mathrm{F} & \mathrm{G} & \mathrm{Y} & \mathrm{T} & \mathrm{V} & \mathrm{N} & \mathrm{S} & \mathrm{T}\end{array}$ \\
\hline
\end{tabular}

FIGURE 3 | Conservation of the mutated amino acids. Alignment of the CLCN7 proteins, showing the conservation of the mutated residues among different species. p. Met560Val transition is indicated by the red arrow.

TABLE 4 | Summary of the CLCN7 mutation in this family with ADO II.

\begin{tabular}{|c|c|c|c|c|c|c|c|c|c|c|}
\hline \multirow[t]{2}{*}{$\begin{array}{l}\text { Variant } \\
\text { (Missense) }\end{array}$} & \multicolumn{2}{|c|}{ Numbers } & \multicolumn{2}{|c|}{ Rarity in gnomAD } & \multicolumn{2}{|c|}{$\begin{array}{c}\text { Conservation (Extremely } \\
\text { conserved) }\end{array}$} & \multicolumn{4}{|c|}{ Pathogenic prediction (Damaging) } \\
\hline & Patients & Carrier & $\begin{array}{l}\text { PopMax } \\
\text { AF }\end{array}$ & $\begin{array}{l}\text { Allele } \\
\text { count }\end{array}$ & $\begin{array}{l}\text { Phylop } \\
\text { score }\end{array}$ & $\begin{array}{l}\text { PhastCon } \\
\text { score }\end{array}$ & $\begin{array}{l}\text { MutationT- } \\
\text { aster } \\
\text { score }\end{array}$ & MPC & $\begin{array}{l}\text { CADD } \\
\text { score } \\
\text { Phred }\end{array}$ & RVIS\% \\
\hline $\begin{array}{l}\text { c.1678A > G } \\
\text { p.Met560Val }\end{array}$ & 3 & 1 & $\begin{array}{l}9.00058 \mathrm{E}- \\
06\end{array}$ & 1 & 6.111 & 1 & 0.999 & 1.0788 & 24.3 & $7.04 \%$ \\
\hline
\end{tabular}

PopMax AF, Maximum allele frequency in any one population; MPC, mutant prevention concentration; CADD, Combined Annotation Dependent Depletion; and RVIS, Residual Variation Intolerance Score.

involved in the type $\mathrm{H}$ formation (Bollerslev et al., 2013; Sivaraj and Adams, 2016; Kim et al., 2018; Peng et al., 2020). Thus, we selected them to see if they have been altered in ADO II patients. Surprisingly, the level of TRAP-5b, PDGF-BB, VEGF, and SLIT3 showed a remarkable increase in ADO II patients compared with the 15 control groups with matched age and sex (Figures 4A-D). To further confirm the possible effect of type $\mathrm{H}$ vessels in this kindred, we purified the PBMCs from the patients and control normal subjects. Then, the collected preosteoclast condition medium from osteoclastic-induced PBMCs has been 

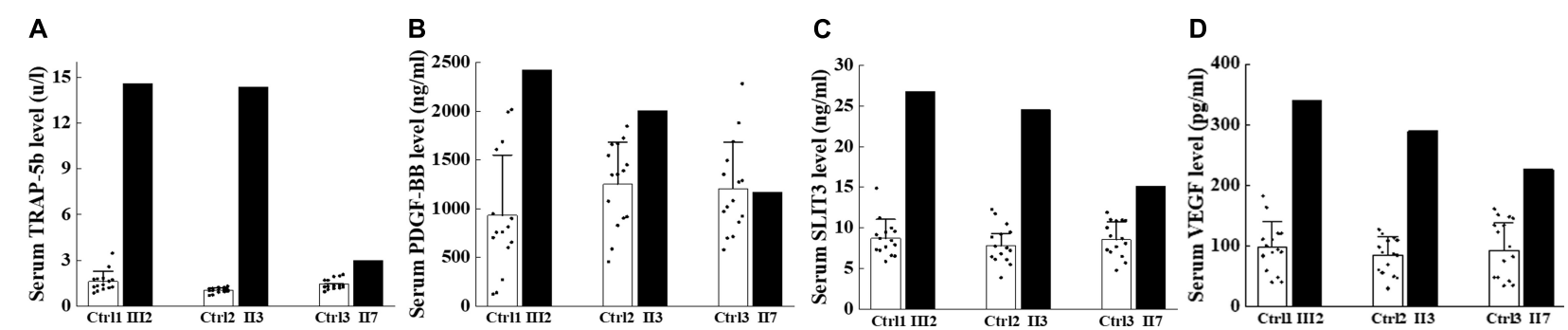

FIGURE 4 | Expression of factors secreted by osteoclast lineage cells elevated in the affected patients. Serum analysis of ADO II subjects and age-matched and sex-matched. (A) Expression of serum TRAP-5b. (B) Expression of serum PDGF-BB. (C) Expression of serum SLIT3. (D) Expression of serum VEGF. Number of controls $=15$. Data are shown as mean \pm SD.
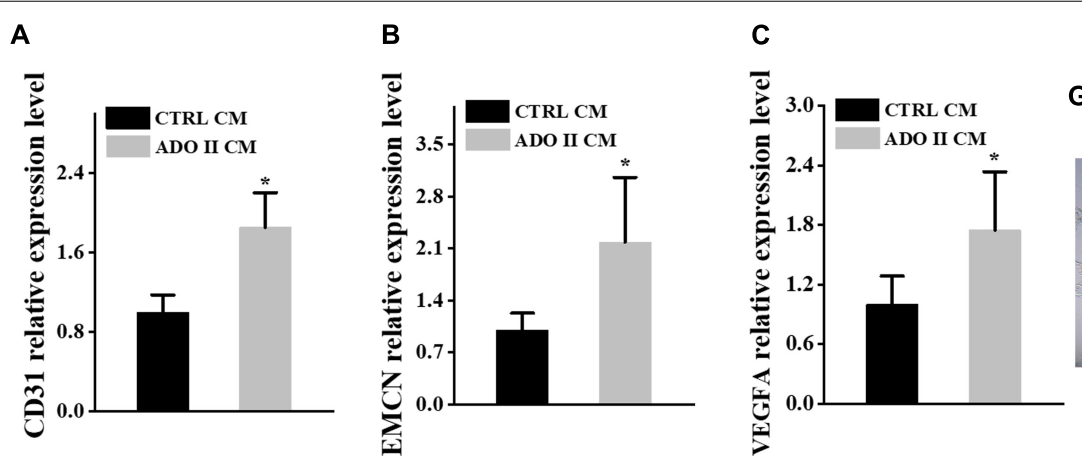

$\mathbf{G}$

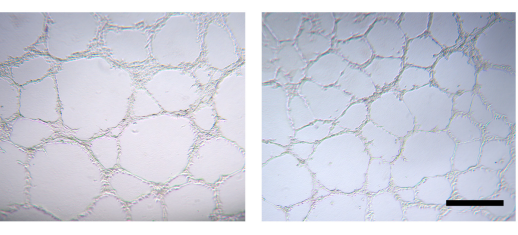

CTRL CM

ADO II CM
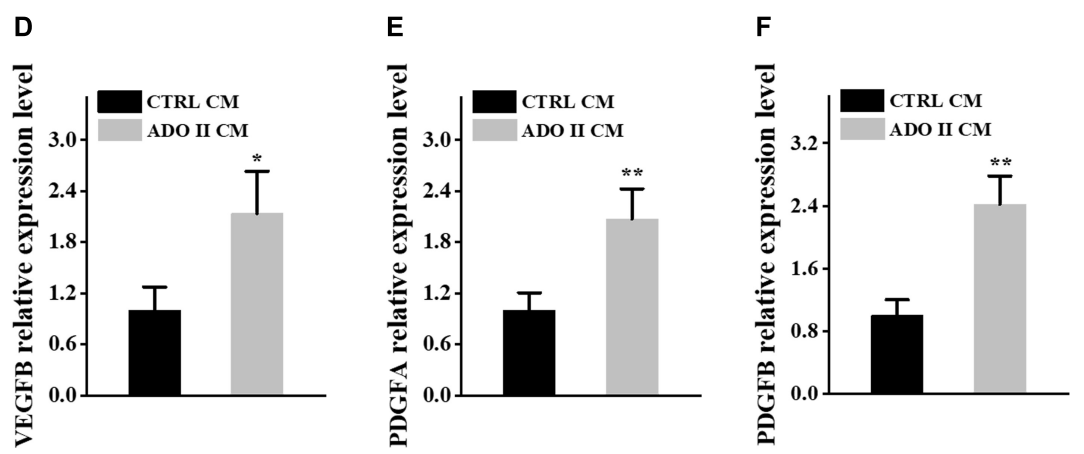

H

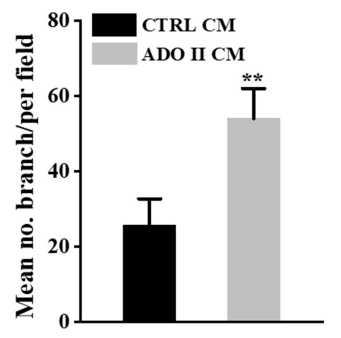

FIGURE 5 | Preosteoclast-conditioned medium from ADO II patients promotes vessel formation in vitro. HMECs were treated with a preosteoclast-conditioned medium from ADO Il patients or control groups. (A,B) qRT-PCR analysis of the relative levels of CD31 (A), EMCN (B), VEGFA (C), VEGFB (D), PDGFA (E), and PDGFB (F) in HMECs. (G) Representative images of tube formation. (H) Quantification of tube branch numbers per field. CTRL CM, control conditioned medium; ADO $\|\mathrm{CM}, \mathrm{ADO}\| \mathrm{l}$ conditioned medium. These experiments were replicated three times. Data are shown as mean $\pm \mathrm{SD}$. ${ }^{\star} P<0.05$ and ${ }^{* *} P<0.01$.

used to culture the HMECs. As expected, the expression of CD31, $E M C N$, and vessel growth factors, including VEGFA, VEGFB, $P D G F A$, and $P D G F B$, has increased in the cells treated with preosteoclast-conditioned medium from ADO II cells compared with the cells from control individuals (Figures 5A-F). Moreover, the tube formation also has been promoted by the ADO IIconditioned medium (Figures 5G,H). Even the expression of RUNX2 was not altered by the conditioned medium from patients; other osteogenic markers in hBMSCs, such as ALPL and $S P 7$, elevated (Figures 6A-C). Consistent with these results, both ALP activity and ALP staining showed a significant difference between the two groups (Figures 6D,E). Together, these data suggested that the CLCN7 mutation might cause the bone accrual partially because of the elevated coupling of bone formation with type $\mathrm{H}$ formation.

\section{DISCUSSION}

Osteopetrosis is a rare genetic condition of increased bone mass and density generally due to a defect of bone resorption. The common complications are confined to the skeleton, including bone fracture, bone pain, osteomyelitis, and rare bone marrow failure (Bénichou et al., 2000). Bone pain on the back was described in three affected patients and fracture on the hip of the proband. Their prominent radiographic signatures of vertebral 


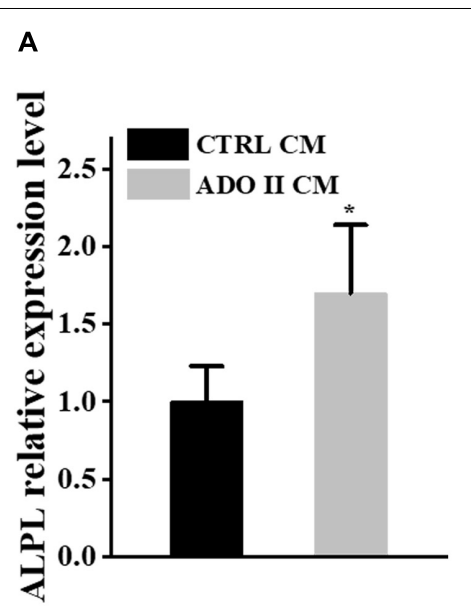

D

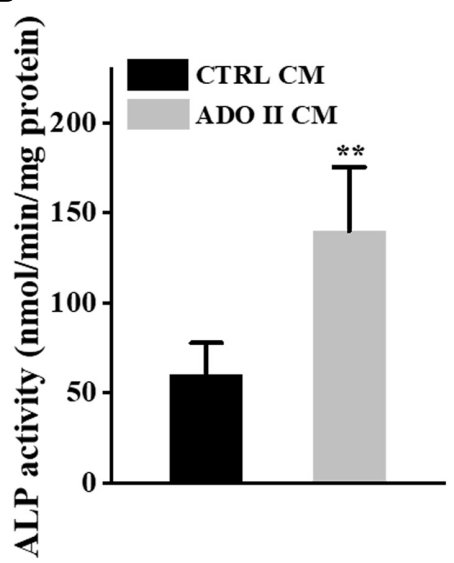

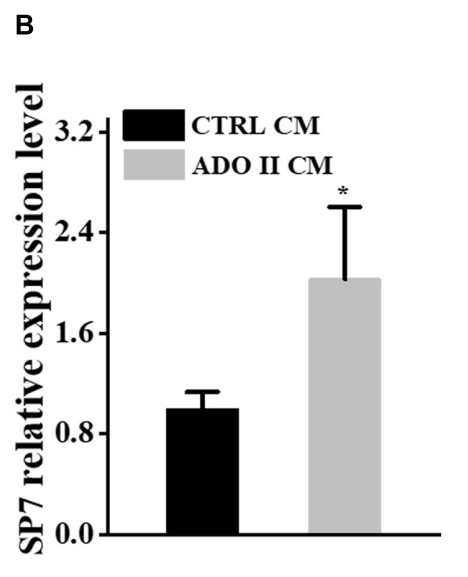

$\mathbf{E}$

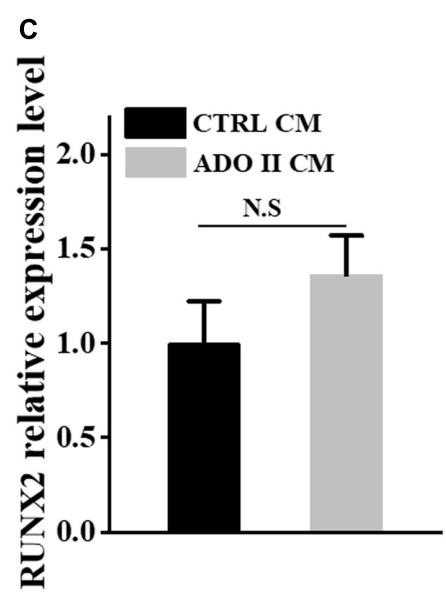

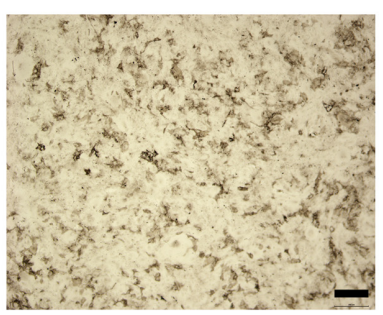

CTRL CM

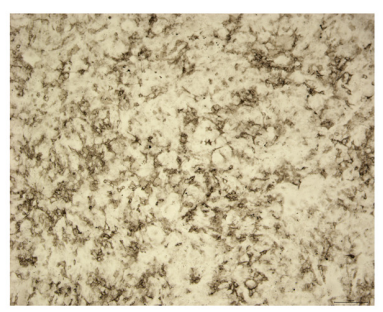

ADO II CM

FIGURE 6 | Preosteoclast-conditioned medium from ADO || patients enhances osteoblastic differentiation in vitro. BMSCs were treated with a preosteoclast-conditioned medium from ADO II patients or control groups. (A-C) qRT-PCR analysis of the relative levels of $A L P L$ (A), SP7 (B), and RUNX2 (C) in BMSCs. (D) ALP activity in BMSCs. (E) Representative images of ALP staining in BMSCs. Scale bar $=300 \mu \mathrm{m}$. These experiments were replicated three times. Data are shown as mean $\pm \mathrm{SD}$. ${ }^{\star} P<0.05$ and ${ }^{\star \star} P<0.01$.

endplates ("rugger-jersey spine") and diffused bone sclerosis were found in three affected patients.

The mutation analysis in this family was in agreement with the clinical diagnosis of ADO-II. Previous studies that reported several mutations in CLCN7 could result in severe recessive, dominant, and intermediate osteopetrosis (Frattini et al., 2003). Currently, genetic and molecular diagnoses were available for patients with ADO II, especially to the missense mutations in the CLCN7 gene (Bollerslev et al., 2013). Above $70 \%$ of patients harbored heterozygous dominant-negative mutations of the CLCN7 gene (Cleiren et al., 2001). These CLCN7-related mutations are usually located in different structures of its protein, such as intramembrane $\alpha$ helices, extracellular loops, Cl-binding sites, and CBS domains (Pang et al., 2016; Jentsch and Pusch, 2018). We identified a heterozygous variant p.Met 560 Val located in the loop between helix $\mathrm{N}$ and helix $\mathrm{O}$ in three patients and an unaffected carrier. There was only one allele of the identified mutation in gnomAD and was not presented in East Asian populations. Additionally, Steven et al. have estimated the penetrance of ADO II to be approximately 66\% (62 clinically affected individuals/94 subjects with the gene mutation), which means among the individuals with CLCN7 mutations, one third were asymptomatic gene carriers without osteopetrosisrelated signs in clinical, biochemical, and radiological results (Waguespack et al., 2003). Thus, the carrier did not present the related osteosclerotic bone associated with the incomplete penetrance. The phenotypical and genetic heterogeneity and incomplete penetrance remain unclear in skeletal dysplasia (Alam et al., 2017; Chen et al., 2020). It is likely to be related to the environmental factors, methylated gene modification, the complex interaction between other genes and CLCN7, and even some unidentified loci (Zhang et al., 2009; Leisle et al., 2011; Boudin et al., 2016), which need more further studies to elucidate.

The previous investigation indicated that $\mathrm{ADO}$ was one of the osteoclast-rich forms of osteopetrosis (Bollerslev et al., 2013). The bone biopsies from patients with ADO showed increased size and number of osteoclasts (Bollerslev et al., 1993). Chen et al. revealed that c.1856C $>\mathrm{T}$ mutation in CLCN7 identified in an ADO II case resulted in enhanced but hypofunctional osteoclastogenesis (Chen et al., 2016). Besides, previous studies 
showed that the serum TRAP-5b was significantly elevated in osteoclast-rich ADO II mice and patients (Chen et al., 2016; Alam et al., 2017). Consistent with these studies, the elevated serum TRAP-5b was also found in these patients with ADO II (Alatalo et al., 2004). The prominently elevated biochemical measurements of TRAP-5b suggested that the variant affected the function of osteoclast and indicated the molecular feature to be osteoclast-rich osteopetrosis in this family.

Osteopetrosis is a clinically heterogenetic disorder. In this Chinese family with the CLCN7 variant, the serum bone formation markers (OC, TPINP, and PTH) were at the upper limit range in the proband. They also elevated in the proband's mother (II3), and the level of OC increased remarkably in the aunt (II7). The variable level of bone formation markers in the three affected patients might be associated with the characterization of clinical heterogeneity or some factors, such as age, lifestyle, and other environmental stimulus (Lundberg et al., 2018; Chevalier et al., 2020). Taken together, the upregulated or upper limit range of serum bone formation markers implied that the bone formation increased. It is extensively reported that the coupling of angiogenesis with osteogenesis plays a great role in bone modeling and remodeling (Phan et al., 2004; Ramasamy et al., 2014; Xie et al., 2014; Yang et al., 2017, 2019; Chen et al., 2018; Li et al., 2018). Previous findings revealed that PDGF-BB secreted by preosteoclasts could stimulate angiogenesis during coupling with osteogenesis (Xie et al., 2014). Furthermore, we demonstrated that Reg1cp mutation potentially caused high bone mass syndrome by regulating the coupling of angiogenesis with osteogenesis (Yang et al., 2019). Other studies revealed that the secret factors, including VEGF and SLIT3 by osteoclast lineage cells, could regulate type $\mathrm{H}$ formation during bone regeneration (Xu et al., 2018; Peng et al., 2020). Based on these findings, we investigated if this CLCN7 mutation contributed to the increased bone mass by regulating the process of angiogenesis and osteogenesis. Intriguingly, we found that the levels of PDGF$\mathrm{BB}, \mathrm{VEGF}$, and SLIT3 were increased in ADO II individuals. Of note, the conditioned medium from PBMCs of ADO II patients promoted vessel formation of HMECs as well as osteogenic differentiation of hBMSCs. These results gave some new insights into the pathogenesis in this family.

In this study, we identified a novel missense variant (p.Met560Val) in CLCN7 through whole-genome sequencing and detected it in all affected family members by Sanger sequence. The

\section{REFERENCES}

Abarrategi, A., Mian, S. A., Passaro, D., Rouault-Pierre, K., Grey, W., and Bonnet, D. (2018). Modeling the human bone marrow niche in mice: from host bone marrow engraftment to bioengineering approaches. J. Exp. Med. 215, 729-743. doi: $10.1084 /$ jem.20172139

Alam, I., McQueen, A. K., Acton, D., Reilly, A. M., Gerard-O’Riley, R. L., Oakes, D. K., et al. (2017). Phenotypic severity of autosomal dominant osteopetrosis type II (ADO2) mice on different genetic backgrounds recapitulates the features of human disease. Bone 94, 34-41. doi: 10.1016/j.bone.2016.10.016

Alatalo, S. L., Ivaska, K. K., Waguespack, S. G., Econs, M. J., Väänänen, K., and Halleen, J. M. (2004). Osteoclast-derived serum tartrate-resistant acid rarity, conservation, and pathogenic predication all supported that this CLCN7 mutation might be a disease-causing one. Furthermore, the in vitro experiments showed that the variant promoted the vessel formation and osteogenic differentiation in this family. To conclude, we presented a novel heterozygous mutation (p.Met560Val) in CLCN7 segregated with ADO II in this Chinese family and revealed that it might be associated with the increased type $\mathrm{H}$ vessel formation and bone formation.

\section{DATA AVAILABILITY STATEMENT}

The whole-genome sequencing data were deposited on the Genbank (Sequence Read Archive) database with the accession no. PRJNA669897.

\section{ETHICS STATEMENT}

The studies involving human participants were reviewed and approved by Ethics Committee of the Xiangya Hospital of Central South University. The patients/participants provided their written informed consent to participate in this study. Written informed consent was obtained from the individual(s) for the publication of any potentially identifiable images or data included in this article.

\section{AUTHOR CONTRIBUTIONS}

HP designed the experiments, performed whole-genome sequencing analysis, carried out most of the experiments, and drafted the manuscript. TW and $\mathrm{H}-\mathrm{BH}$ recruited the patients. TW supervised the experiments, analyzed results, and proofread the manuscript. All authors were involved in the final approval of the submitted version.

\section{ACKNOWLEDGMENTS}

The authors would like to thank the family for their participation in this study. The authors gratefully acknowledge Prof. Stephen P. Robertson at the University of Otago, providing the platform and the method of genetic analysis.

phosphatase 5b in Albers-Schonberg disease (type II autosomal dominant osteopetrosis). Clin. Chem. 50, 883-890. doi: 10.1373/clinchem.2003.029355

Barvencik, F., Kurth, I., Koehne, T., Stauber, T., Zustin, J., Tsiakas, K., et al. (2014). CLCN7 and TCIRG1 mutations differentially affect bone matrix mineralization in osteopetrotic individuals. J. Bone Miner. Res. 29, 982-991. doi: 10.1002/jbmr. 2100

Bénichou, O., Cleiren, E., Gram, J., Bollerslev, J., de Vernejoul, M.-C., and Van Hul, W. (2001). Mapping of autosomal dominant osteopetrosis type II (AlbersSchönberg disease) to chromosome 16p13.3. Am. J. Hum. Genet. 69, 647-654. doi: $10.1086 / 323132$

Bénichou, O. D., Laredo, J. D., and de Vernejoul, M. C. (2000). Type II autosomal dominant osteopetrosis (Albers-Schönberg disease): clinical and radiological 
manifestations in 42 patients. Bone 26, 87-93. doi: 10.1016/S8756-3282(99) 00244-6

Bollerslev, J., Henriksen, K., Frost Nielsen, M., Brixen, K., and Van Hul, W. (2013). Autosomal dominant osteopetrosis revisited: lessons from recent studies. Eur. J. Endocrinol. 169, R39-R57. doi: 10.1530/EJE-13-0136

Bollerslev, J., Marks, S. C. Jr., Pockwinse, S., Kassem, M., and Brixen, K. (1993). Ultrastructural investigations of bone resorptive cells in two types of autosomal dominant osteopetrosis. Bone 14, 865-869. doi: 10.1016/8756-3282(93)90 316-3

Boudin, E., Fijalkowski, I., Hendrickx, G., and Van Hul, W. (2016). Genetic control of bone mass. Mol. Cell. Endocrinol. 432, 3-13. doi: 10.1016/j.mce.2015.12.021

Capulli, M., Maurizi, A., Ventura, L., Rucci, N., and Teti, A. (2015). Effective small interfering RNA therapy to treat CLCN7-dependent autosomal dominant osteopetrosis type 2. Mol. Ther. Nucleic Acids 4:e248. doi: 10.1038/mtna. 2015.21

Chen, X., Wang, Z., Duan, N., Zhu, G., Schwarz, E. M., and Xie, C. (2018). Osteoblast-osteoclast interactions. Connect. Tissue Res. 59, 99-107. doi: 10. 1080/03008207.2017.1290085

Chen, X., Zhang, K., Hock, J., Wang, C., and Yu, X. (2016). Enhanced but hypofunctional osteoclastogenesis in an autosomal dominant osteopetrosis type II case carrying a c.1856C $>\mathrm{T}$ mutation in CLCN7. Bone Res. 4:16035. doi: 10.1038/boneres.2016.35

Chen, Y.-H., Grigelioniene, G., Newton, P. T., Gullander, J., Elfving, M., Hammarsjö, A., et al. (2020). Absence of GP130 cytokine receptor signaling causes extended Stüve-Wiedemann syndrome. J. Exp. Med. 217:e20191306. doi: 10.1084/jem.20191306

Chevalier, C., Kieser, S., Çolakoğlu, M., Hadadi, N., Brun, J., Rigo, D., et al. (2020). Warmth prevents bone loss through the gut microbiota. Cell Metab. 32, 575.e7-590.e7. doi: 10.1016/j.cmet.2020.08.012

Cleiren, E., Bénichou, O., Van Hul, E., Gram, J., Bollerslev, J., Singer, F. R., et al. (2001). Albers-Schonberg disease (autosomal dominant osteopetrosis, type II) results from mutations in the ClCN7 chloride channel gene. Hum. Mol. Genet. 10, 2861-2867. doi: 10.1093/hmg/10.25.2861

Coudert, A. E., Del Fattore, A., Baulard, C., Olaso, R., Schiltz, C., Collet, C., et al. (2014). Differentially expressed genes in autosomal dominant osteopetrosis type II osteoclasts reveal known and novel pathways for osteoclast biology. Lab. Investig. 94, 275-285. doi: 10.1038/labinvest.2013.140

Del Fattore, A., Cappariello, A., and Teti, A. (2008). Genetics, pathogenesis and complications of osteopetrosis. Bone 42, 19-29. doi: 10.1016/j.bone.2007. 08.029

Frattini, A., Pangrazio, A., Susani, L., Sobacchi, C., Mirolo, M., Abinun, M., et al. (2003). Chloride channel ClCN7 mutations are responsible for severe recessive, dominant, and intermediate osteopetrosis. J. Bone Miner. Res. 18, 1740-1747. doi: 10.1359/jbmr.2003.18.10.1740

Hao, X., Gu, H., Chen, C., Huang, D., Zhao, Y., Xie, L., et al. (2019). Metabolic imaging reveals a unique preference of symmetric cell division and homing of leukemia-initiating cells in an endosteal niche. Cell Metab. 29, 950.e6-965.e6. doi: 10.1016/j.cmet.2018.11.013

Hayashi, M., Nakashima, T., Yoshimura, N., Okamoto, K., Tanaka, S., and Takayanagi, H. (2019). Autoregulation of osteocyte sema3a orchestrates estrogen action and counteracts bone aging. Cell Metab. 29, 627.e5-637.e5. doi: 10.1016/j.cmet.2018.12.021

Jentsch, T. J., and Pusch, M. (2018). CLC chloride channels and transporters: structure, function, physiology, and disease. Physiol. Rev. 98, 1493-1590. doi: 10.1152/physrev.00047.2017

Kim, B. J., Lee, Y. S., Lee, S. Y., Baek, W. Y., Choi, Y. J., Moon, S. A., et al. (2018). Osteoclast-secreted SLIT3 coordinates bone resorption and formation. J. Clin. Invest. 128, 1429-1441. doi: 10.1172/JCI91086

Kusumbe, A. P., Ramasamy, S. K., and Adams, R. H. (2014). Coupling of angiogenesis and osteogenesis by a specific vessel subtype in bone. Nature 507, 323-328. doi: 10.1038/nature13145

Langen, U. H., Pitulescu, M. E., Kim, J. M., Enriquez-Gasca, R., Sivaraj, K. K., Kusumbe, A. P., et al. (2017). Cell-matrix signals specify bone endothelial cells during developmental osteogenesis. Nat. Cell Biol. 19, 189-201. doi: 10.1038/ ncb3476

Leisle, L., Ludwig, C. F., Wagner, F. A., Jentsch, T. J., and Stauber, T. (2011). ClC-7 is a slowly voltage-gated $2 \mathrm{Cl}-/ 1 \mathrm{H}+$-exchanger and requires
Ostm1 for transport activity. EMBO J. 30, 2140-2152. doi: 10.1038/emboj. 2011.137

Li, C., Xiao, Y., Yang, M., Su, T., Sun, X., Guo, Q., et al. (2018). Long noncoding RNA Bmncr regulates mesenchymal stem cell fate during skeletal aging. J. Clin. Invest. 128, 5251-5266. doi: 10.1172/JCI99044

Li, X., Sun, X., and Carmeliet, P. (2019). Hallmarks of endothelial cell metabolism in health and disease. Cell Metab. 30, 414-433. doi: 10.1016/j.cmet.2019.08.011

Lundberg, J. O., Carlström, M., and Weitzberg, E. (2018). Metabolic effects of dietary nitrate in health and disease. Cell Metab. 28, 9-22. doi: 10.1016/j.cmet. 2018.06.007

Maurizi, A., Capulli, M., Curle, A., Patel, R., Ucci, A., Côrtes, J. A., et al. (2019). Extra-skeletal manifestations in mice affected by Clcn7-dependent autosomal dominant osteopetrosis type 2 clinical and therapeutic implications. Bone Res. 7:17. doi: 10.1038/s41413-019-0055-X

Pang, Q., Chi, Y., Zhao, Z., Xing, X., Li, M., Wang, O., et al. (2016). Novel mutations of CLCN7 cause autosomal dominant osteopetrosis type II (ADO-II) and intermediate autosomal recessive osteopetrosis (IARO) in Chinese patients. Osteoporos. Int. 27, 1047-1055. doi: 10.1007/s00198-015-3320-x

Peng, Y., Wu, S., Li, Y., and Crane, J. L. (2020). Type H blood vessels in bone modeling and remodeling. Theranostics 10, 426-436. doi: 10.7150/thno.34126

Phan, T. C. A., Xu, J., and Zheng, M. H. (2004). Interaction between osteoblast and osteoclast: impact in bone disease. Histol. Histopathol. 19, 1325-1344. doi: 10.14670/HH- 19.1325

Ramasamy, S. K., Kusumbe, A. P., Wang, L., and Adams, R. H. (2014). Endothelial Notch activity promotes angiogenesis and osteogenesis in bone. Nature 507, 376-380. doi: 10.1038/nature13146

Rodriguez-Laguna, L., Agra, N., Ibañez, K., Oliva-Molina, G., Gordo, G., Khurana, N., et al. (2019). Somatic activating mutations in PIK3CA cause generalized lymphatic anomaly. J. Exp. Med. 216, 407-418. doi: 10.1084/jem.2018 1353

Sivaraj, K. K., and Adams, R. H. (2016). Blood vessel formation and function in bone. Development 143, 2706-2715. doi: 10.1242/dev.136861

Sobacchi, C., Schulz, A., Coxon, F. P., Villa, A., and Helfrich, M. H. (2013). Osteopetrosis: genetics, treatment and new insights into osteoclast function. Nat. Rev. Endocrinol. 9, 522-536. doi: 10.1038/nrendo.2013.137

Tolar, J., Teitelbaum, S. L., and Orchard, P. J. (2004). Osteopetrosis. N. Engl. J. Med. 351, 2839-2849. doi: 10.1056/NEJMra040952

Verkman, A. S., and Galietta, L. J. V. (2009). Chloride channels as drug targets. Nat. Rev. Drug Discov. 8, 153-171. doi: 10.1038/nrd2780

Waguespack, S. G., Hui, S. L., DiMeglio, L. A., and Econs, M. J. (2007). Autosomal dominant osteopetrosis: clinical severity and natural history of 94 subjects with a chloride channel 7 gene mutation. J. Clin. Endocrinol. Metab. 92, 771-778. doi: 10.1210/jc.2006-1986

Waguespack, S. G., Koller, D. L., White, K. E., Fishburn, T., Carn, G., Buckwalter, K. A., et al. (2003). Chloride channel 7 (ClCN7) gene mutations and autosomal dominant osteopetrosis, type II. J. Bone Miner. Res. 18, 1513-1518. doi: 10.1359/ jbmr.2003.18.8.1513

Wang, C., Hockerman, S., Jacobsen, E. J., Alippe, Y., Selness, S. R., Hope, H. R., et al. (2018). Selective inhibition of the p $38 \alpha$ MAPK-MK2 axis inhibits inflammatory cues including inflammasome priming signals. J. Exp. Med. 215, 1315-1325. doi: $10.1084 /$ jem. 20172063

Weinert, S., Jabs, S., Supanchart, C., Schweizer, M., Gimber, N., Richter, M., et al. (2010). Lysosomal pathology and osteopetrosis upon loss of H+-driven lysosomal Cl-accumulation. Science 328, 1401-1403. doi: 10.1126/science. 1188072

Xiao, Y.-Z., Yang, M., Xiao, Y., Guo, Q., Huang, Y., Li, C.-J., et al. (2020). Reducing hypothalamic stem cell senescence protects against aging-associated physiological decline. Cell Metab. 31, 534.e5-548.e5. doi: 10.1016/j.cmet.2020. 01.002

Xie, H., Cui, Z., Wang, L., Xia, Z., Hu, Y., Xian, L., et al. (2014). PDGF-BB secreted by preosteoclasts induces angiogenesis during coupling with osteogenesis. Nat. Med. 20, 1270-1278. doi: 10.1038/nm.3668

Xu, R., Yallowitz, A., Qin, A., Wu, Z., Shin, D. Y., Kim, J.-M., et al. (2018). Targeting skeletal endothelium to ameliorate bone loss. Nat. Med. 24, 823-833. doi: 10.1038/s41591-018-0020-z

Yang, M., Guo, Q., Peng, H., Xiao, Y.-Z., Xiao, Y., Huang, Y., et al. (2019). Krüppel-like factor 3 inhibition by mutated lncRNA Reglcp results in human 
high bone mass syndrome. J. Exp. Med. 216, 1944-1964. doi: 10.1084/jem.2018 1554

Yang, M., Li, C.-J., Sun, X., Guo, Q., Xiao, Y., Su, T., et al. (2017). MiR497195 cluster regulates angiogenesis during coupling with osteogenesis by maintaining endothelial Notch and HIF-1 $\alpha$ activity. Nat. Commun. 8, 1-11. doi: 10.1038/ncomms 16003

Zhang, Z., He, J., Zhang, H., Hu, W., Fu, W., Gu, J., et al. (2009). Identification of the CLCN7 gene mutations in two Chinese families with autosomal dominant osteopetrosis (type II). J. Bone Miner. Metab. 27, 444-451. doi: 10.1007/s00774009-0051-0
Conflict of Interest: The authors declare that the research was conducted in the absence of any commercial or financial relationships that could be construed as a potential conflict of interest.

Copyright (c) 2020 Peng, He and Wen. This is an open-access article distributed under the terms of the Creative Commons Attribution License (CC BY). The use, distribution or reproduction in other forums is permitted, provided the original author(s) and the copyright owner(s) are credited and that the original publication in this journal is cited, in accordance with accepted academic practice. No use, distribution or reproduction is permitted which does not comply with these terms. 